\title{
Textile reinforced structure: A Review
}

\author{
Prof.(Dr). S.S. Bhattacharya ${ }^{1}$, Mrs.S.A. Agrawal ${ }^{12}$, \\ ${ }^{1}$ Department of Textile Engineering, the Maharaja Sayajirao University, Gujarat, India. \\ ${ }^{2}$ Corresponding author: Mrs.S.A. Agrawal.sweetyagrawal88@yahoo.com
}

\begin{abstract}
Textile composite structure has emerged as huge category of composite materials which is known for its adaptability and ease of making due already available traditional methods of manufacturing. Composite materials are replacing day by day the conventional metallic materials due to their light weight, high strength, design flexibility and long life. Textile structures are engineered and fabricated to meet worldwide structural applications. The use of textile materials like fibres, fabrics as reinforcement in designing and generating improved materials for different applications has increased due to its outstanding properties in terms of easy handling, shapability, adaptability and structural complexity. The demand for lightweight products that consume less energy in aviation, wind energy, motor vehicles etc. have added to this.
\end{abstract}

Keywords: Compositestructure, Matrix, Reinforcement, Textile reinforcement, Laminates

\section{INTRODUCTION}

Today with the advancement of technology a need is created for versatile product development. A single material cannot satisfy this demand, so existence of composites became possible. Composites are the most sought materials in terms of their utility, properties, adaptability and applications.[1] Composites due to their high strength to weight ratio, excellent chemical resistance, superior electrical and thermal conductivity and many other properties has increased its use in an ever-growing number of applications.

Textile reinforcement structure can be made of fibers, yarns or fabrics (woven, braided, knitted or non-woven) and are generally flexible. The application of traditional textile technology to organize high performance fibers for composite material applications has provided a route to combining highly tailored materials with enhanced process ability. [2]

\section{COMPOSITE}

Composite materials have been used quite successfully for decades within industry sectors such as aerospace, maritime, transportation, infrastructure and consumer goods. These materials consist of high-performance fibers such as carbon, glass and aramid, which are bound together within a matrix of polymer material such as epoxy, polyester, etc. The inherent high strength-weight and stiffness- weight ratios and fatigue and corrosion resistance of composite materials give them the ability to produce components with significant weight and performance advantages over metal parts [3-5]. The physical behavior of composite materials is quite different from that of most common engineering materials that are homogeneous and isotropic. Metals will generally have similar composition regardless of where or in what orientation a sample is taken. On the other hand, the makeup and physical properties of composites will vary with location and orientation of the principal axes. These materials are termed anisotropic, which means they exhibit different properties when tested in different directions. [6] Composite is made of two components: reinforcement material and matrix. [7] Composite Material are two inherently different materials that when combined produce material with properties that exceed the constituent materials. Composite materials are made by combining two or more materials to give a unique combination of properties. [4]

\section{TEXTILECOMPOSITE}

Textile structures have long been known as prime reinforcement for fiber reinforced composite applications due to their unique properties, such as easy handling, shapability, adaptability and structural complexity. [8]Textile structure composites have higher strength to weight ratio. [9]High tensile strength and stiffness as well as high fatigue life, low weight and excellent chemical resistance are certain major attributes of Fiberreinforced composites, which make them highly an attractive material for distinctive and relinquishedapplications.[10] 
Textile composite is made of a textile reinforcement structure and a matrix material. Textile reinforcement structure can be made of fibers, yarns and fabrics (woven, braided, knit, nonwoven) are generally flexible. Matrix material can be thermoplastic or thermoset polymers. Textile composite can be flexible or rigid.

Textile composite is made up of textile reinforcement structure and a matrix.

a) Reinforcing materials: It can be made of fibers, yarns or fabrics (woven, braided, knit or nonwoven)

- $\quad$ Natural fiber: Jute, hemp, flax

- Synthetic organic fibers: Carbon, aramid etc.

- Synthetic inorganic fibers: Glass, silicon carbide etc.

- Fillers: Calcium carbonate

b) Matrix

- Thermosetting polymers

- Thermoplastic polymers

- Ceramics

- Metal

c) Interface

Zone across which the matrix and reinforcement interact (Physically, chemically and mechanically)

\subsection{Classification of Textile reinforcement structure}

Textile reinforced structure can be classified as (1) Dimension (2D and 3D) (2) Method of manufacturing (woven, knit, braid and nonwoven) [2] (3) Linearity of reinforcement (linear or nonlinear) (4) Direction of reinforcement $(1,2,3$ or multi) (5) Integration (Laminated or integrated)

\subsection{Types of Laminates}

1. Symmetric laminates: A symmetric laminate has both geometric and material symmetry with respect to the mid-surface.

2. Asymmetric Laminates: This laminate is characterized by having its layers arranged in an asymmetric fashion with respect to the mid-surface.

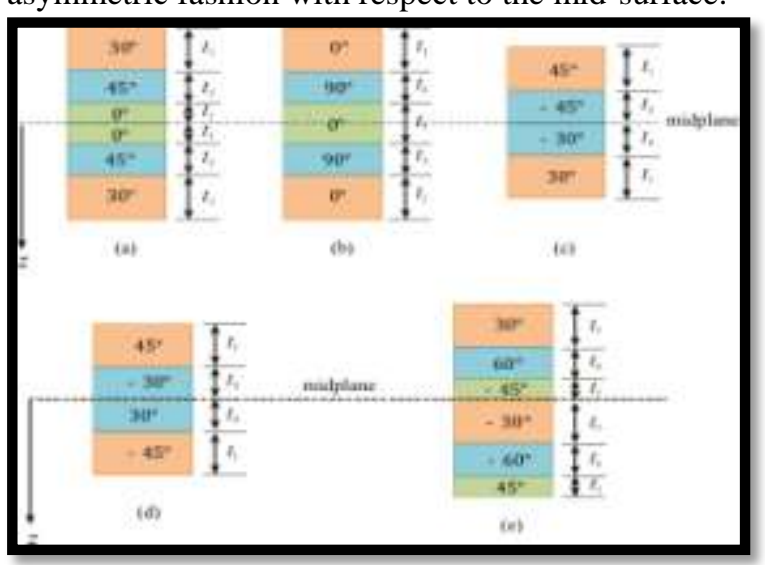

(a) Symmetric laminate (b) Cross-ply laminate (c) Angle-ply laminate (d) Anti-symmetric laminate and (e) Balanced laminate [11]

\section{APPLICATION}

Composite materials due to have wide range of applications like bullet-proofing, marine \& underwater vehicles, aerospace vehicles, automotive structures and geotextiles etc. They have replaced metal and metal alloys successfully in many applications including automotive, aerospace, electronics, military and recreations. For example, glass composite is used to make ship hulls [12], Boeing`s787 Dream liners the first commercial aircraft in which major elements are made of composite materials rather than aluminum alloys. [13] Other application includes drive shafts, side rails, doors, hoods, hinges, seat frames, bumpers, submarines, powerboats, racing yachts, and laminated sailcloth \& interiors like overhead luggage compartments, sidewalls, partitions, cargo liners etc. [9]Structures such as panels, marine structure like boat, ships, submarines and aerospace structures like aero plane, airport pavements, military structures etc. are subjected to severe impact loads. In case of Technical fabrics, these fabrics absorb the energy from the deforming high velocity materials before it completely penetrates the textile matrix. In all these applications, very high stress rate occur during such dynamic loading as large amount of energy is transmitted to the structure in short duration. [14] It is also affected by the composite material parameters like fiber content, thickness, volume, height, stacking sequence, resin used etc. It would be very desirable to be able to relate the extent of damage to the properties of the matrix, fiber, and interphase, along with factors such as reinforcement form. This would facilitate the development of more reliable materials and structures. [15]

\section{CONCLUSION}

Many of our modern technologies require material with distinctive combination of properties that cannot be met by conventional metal alloys, ceramics and polymeric materials. Main characteristics of Textile composite structure are high stiffness, high strength and low density. Other properties depend on product design. Application areas of composites are steadily expanding. Composites are one of the most widely used materials because of their adaptability to different situations and the relative ease of combination with other material to serve specific purpose and exhibit desired properties. Better understanding of functioning of reinforcing fibers in composites materials enable design production of new textile based composites for a wide range of applications. 


\section{REFERENCES}

[1] Naveen V Padaki, R Alagirusamy\& B L Deopura, Low velocity impact behavior of textile reinforced composites, Indian Journal of Fibre\& Textile Research, Vol. 33, June 2008, pp. 189-202

[2] Rajeev Varshney et al, Innovations in Textile Composite Designing and Their Applications, International Journal of Computer Applications (0975 - 8887),1-3

[3] Lamontia, M.A., Gruber, M.B. Smoot, M.A. Sloan, J. and Gillespie, Jr., J.W. (1995.Performance of a Filament Wound Graphite/Thermoplastic Composite RingStiffened Pressure Hull Model, Journal ofThermoplastic Composite Materials, 8:1536. www.wikipedia.com "Carbon fiber reinforced composites"

[4] M K Bannister, Development and application of advanced textile composites,Proc. Instn Mech. Engrs Vol. 218 Part L: J. Materials: Design and Applications, 253-260

[5] Robert M Jones, Mechanics of composite materials CRC Press, 01-Jul-1998

[6] Encyclopaedia of Polymer Scienceand Technology. Composite materials Vol 9, PP 282
[7] Hearle J W S, Text Horizons, 14(6) (1994) 12

[8] SabitAdanur, Wellington Sears Handbook of Industrial Textiles, Technomic publishing Co. Inc, 1995.

[9] Zaki Ahmad, Faleh Al-Sulaiman and B. J. Abdul Aleem, Corrosion Behaviour of Carbon Reinforced Plain-Weave Laminates, Journal of Reinforced Plastics and Composites, 2004 23: 1041, DOI: 10.1177/0731684404035268

[10] nptel.ac.in/courses/101104010/lecture17/17 4.htm

[11] A. Valenza, V. Fiore and G. Bella, Effect of UD Carbon on the Specific Mechanical Properties of Glass Mat Composites for Marine Applications, Journal of composite materials, Vol. 44, No. 11/201006/07/2015

[12] Surface Modelling for Composite Materials - SIAG GD :Retrieved at http://www.ifi.uio.no/siag/problems/grandin $\underline{\mathrm{e} /}$

[13] BarzinMobasher, Mechanics of Fiber and Textile Reinforced Cement Composites CRC Press, 20 Dec 2011

[14] /www.princeton.edu/ ota/disk2/1988/8801/8 80106.PDF. Chapter 3: Polymer matrix composite.

International Journal of Engineering Research and Applications (IJERA) is UGC approved Journal with Sl. No. 4525, Journal no. 47088. Indexed in Cross Ref, Index Copernicus (ICV 80.82), NASA, Ads, Researcher Id Thomson Reuters, DOAJ.

Prof.(Dr). S.S. Bhattacharya. "Textile reinforced structure: A Review." International Journal of Engineering Research and Applications (IJERA) 7.7 (2017): 84-86. 